\title{
SMALL-GROUP TUTORIALS AND OPEN BRAINSTORMING FOR ProbleM-SOLVING IN ENVIRONMENTAL ENGINEERING SYSTEMS
}

\author{
Arun Moorthy ${ }^{1}$, Carolyn Chan ${ }^{2}$ and Warren Stiver ${ }^{2}$ \\ ${ }^{1}$ Biophysics Interdepartmental Program, ${ }^{2}$ School of Engineering \\ University of Guelph, Guelph, ON, Canada \\ [amoorthy;cchan;wstiver]@uoguelph.ca
}

\begin{abstract}
Environmental Engineering Systems is a core-course for undergraduate students at the University of Guelph pursuing degrees in Environmental or Water Resource Engineering. The class is a thorough introduction to many elementary concepts of Chemical and Biological Engineering, including concepts of conservation and reactor system design, and is delivered through lecture, laboratory and tutorial components. At the University of Guelph, Environmental Engineering Systems tutorials are operated in small groups (approx. 20 students), taking advantage of the extensive whiteboards available in the facility to promote open brainstorming as a means to solve problems. Students work in partnerships, but are encouraged to discuss with the other groups in the room, as to come to a consensus solution on a given problem. Instructors (usually 2) float around the room, coaching students as needed, but refrain from providing over-guidance and a final solution; ensuring students be cognizant of problem solving in industrial and/or higher-learning settings. This technique was beneficial to instructors, allowing for the easy identification of specific problem-solving skills students were lacking, and the appropriate corrections to be implemented. There were still some concerns about engaging timid students, and also with students becoming over-dependent on the group dynamic and not performing as well individually.
\end{abstract}

Keywords: Environmental Engineering Systems, Course delivery, Undergraduate education

\section{INTRODUCTION}

Problem analysis is identified as a foundational engineering skill within the accreditation requirements of the Canadian Engineering Accreditation Board[1], ABET [2] and the Washington Accord[3]. Sample problems are widely used as a means to develop problem analysis capabilities. They are included in textbooks, delivered in lectures and tutorials.
The norm is for these sample problems to be in polished form that often belies the true nature of the novice or experts problem analysis process. On their own, sample problems are a passive pedagogical approach and can lead to a dependent, spoon-fed learner.

The tutorials in Environmental Engineering Systems combine THINK ALOUD [4, 5], active and collaborative learning philosophies. The desire is to develop an independent learner who is actively experiencing a more genuine problem analysis process.

This paper will provide a brief description of the course and student expectations, a summary of tutorial and laboratory exercises, and a discussion of our observations from tutorial sections.

\subsection{Course Description}

The course, ENGG 2560 - Environmental Engineering Systems, is a core-component for undergraduate students pursuing degrees in Environmental or Water Resource Engineering[6]. It is a quick but thorough introduction to many concepts of Chemical and Biological Engineering, as well as those more particular to the Environmental discipline, including:

- Units and dimensions

- Mass balance

- Reactors: Batch, Continuous (CSTR, PFR), Systems

- Reaction kinetics: Chemical, Biological

- Equilibrium: Phase, Reaction

- Noise: Principles, Modelling, Control

The students were expected to attend 3 lectures and their allotted tutorial/lab section every week. Additionally, evaluation was based on student performance on three in-class tests, three lab reports (written in pairs), and a final exam. 


\subsection{Student Description}

Most students taking this course were in their second year studying Environmental or Water Resource Engineering. The expectation was that students had taken introductory courses in Chemistry and Differential Calculus, and any prerequisite courses there in.

\section{COURSE DELIVERY}

As noted, the majority of the course contents were delivered through traditional lectures. Additionally, students were expected to participate in a 2-hour tutorial or lab every week. For tutorials, we split the class of 93 into five groups of 20 students with 2 instructors.

\subsection{Tutorials}

Weekly problem sets were provided to students, however the tutorial time was an opportunity for students to work through any course material they saw fit. Figure 1 illustrates the layout of our tutorial room. There were six potential whiteboards for students to work (Labelled A through F), as well as significant desk space. We requested that students do the majority of their brainstorming and solution development on the whiteboards as to allow us to better observe what they were working through and determine how and when to coach them. We also refrained from providing students with solutions, requesting that they come to communal solutions as a tutorial section/class. The intention was to provide students a better understanding of what problem solving entails in industrial/higher-learning settings.

Problem sets were nominally 3 to 8 questions long. Some weeks multiple problem sets were made available, and in others, students were expected to work through their back $\log$ of assignments. At the beginning of the term, all students worked through the same problem sets and at around the same pace. As the term progressed, students worked with less structure, choosing to work through problems according to their needs.

\subsection{Lab component}

In addition to tutorials, there were three practical labs included to support lecture material:

- Batch Reactor Lab: estimate kinetic parameters for the decay of Crystal Violet in a Sodium Hydroxide solution using spectrophotometry.

- Reactor Systems Lab: measure the movement of contaminant (Crystal Violet) through a series of vessels and compare results to numerical solution achieved using a computational model developed in Matlab/Simulink (See Figure 2).

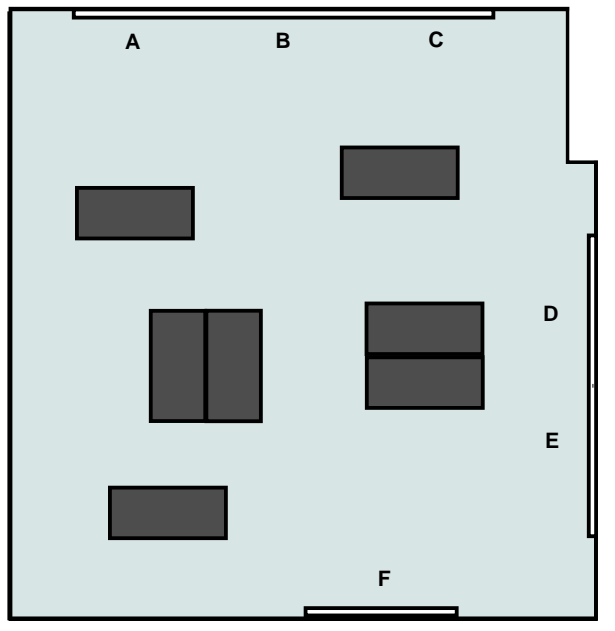

Figure 1: General layout of tutorial room (not to scale). Whiteboards are indicated by letters A through $F$.

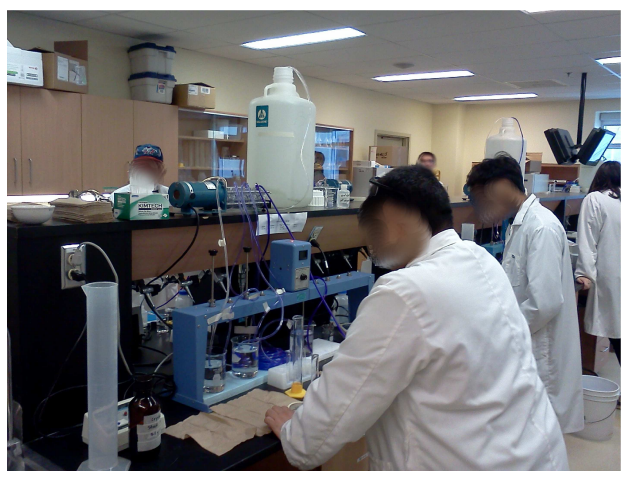

Figure 2: Students performing Reactor Systems laboratory to model the movement of contaminant through a water system.

- Noise Lab: develop a surface map of sound levels and estimate the Room Constant of a specified room based on a series of sound pressure readings using the Indoor Sound Model.

Upon completing the experimental portions of each lab, students were asked to complete a fairly thorough analysis and discussion of their findings, and demonstrate this through a comprehensive report. Analysis included some elementary statistics as well as any qualitative observations. Generally, students chose to work through their lab reports during tutorial slots when approaching due dates, but were instructed that problem sets were still being made available. 


\section{DISCUSSION}

What should be quite apparent is the large coverage of content being delivered to students taking Environmental Engineering Systems. In this discussion we will focus our consideration to observations from the small-group tutorials that we maintained, as the manner in which students were asked to approach questions (group discussions/using easily observable whiteboards) provided us many interesting insights for future iterations of this course.

\subsection{Student aversion to writing}

At the onset of the semester, having students discuss problems with a partner and surrounding groups was not a big obstacle, however, convincing them to write their ideas up on the whiteboard was not as simple a task.

Much of this may have been due to initial timidness. Though students were expected to have taken introductory chemistry and differential calculus courses, it was immediately clear that students would require some time to reengage certain areas of knowledge. As the term went on, most students did become more comfortable with the idea of working out solutions in the public-eye on their allotted whiteboard space.

After overcoming initial timidness, there was still an issue of students not maximizing their whiteboard space. That is, we noticed that students would often use the whiteboard as a space to visualize their final solution for inspection by instructors/other students, but attempt to generate solutions completely in their minds, failing to illustrate sketches, write down given parameters (with units) and state governing equations; overall using poor problem-solving etiquette.

As soon as making this observation (approximately 3 weeks into the term), we continued to encourage students to use their whiteboard space to aid them in brainstorming and developing their solutions. At first, the problem sets were simple enough that students were able to get by without writing down their ideas, but as the term progressed and concepts became further from their comfort zones, most students learned to make excellent use of their whiteboards. It was especially encouraging to see students begin problems drawing schematics representing the situation and identifying what the problem required of them.

\subsection{Careless mistake versus fundamental lack of understanding}

One of the greatest benefits to seeing students develop a solution to a problem is it allows for easy identification of fundamental misunderstandings. At the beginning of the term when students were not as comfortable developing their solutions on the whiteboard, we'd find that students were often obtaining solutions that were incorrect by magnitudes, usually as a result of unit conversion. This type of error is one that will usually get swept aside as a careless mistake. However, as the term went on we were able to realize that these seemingly careless mistakes were often a fundamental lack of understanding of the student.

The most obvious misunderstandings were with respect to unit conversions, where students would regularly incorrectly apply different conversions of concentration (especially with non-standard units), however there were also many concerns regarding what we thought to be simple algebra (issues re-arranging equations) and calculus (issues determining boundary conditions).

Though this was at first a bit dis-heartening, it did aid us as instructors in coaching them through some of their difficulties, and so was ultimately of benefit to both us and the students. It cannot be overstated how easily some of these errors would have been misinterpreted had we simply seen the final solutions on a quiz/assignment.

\subsection{Group dynamic and team building}

Another benefit to the open brainstorming approach was the sense of team we were able to build within each tutorial section. By the end of the term, most students were comfortable communicating with everyone else in the class, sharing their solution methods and asking for help from others without hesitation. This was beneficial to us as instructors as we were often able to shorten our time of direct coaching with individual students, as well as observe how students were coaching each other as to immediately assess the quality of understanding within the group.

As noted, by the end of the term most students had fully embraced the group dynamic, however, It is estimated that somewhere between $10-20 \%$ of the class did not genuinely engage in the approach. A fraction opted not to attend and a fraction continued to work at the desks rather than the whiteboard.

\subsection{Issues of dependence}

One of the natural concerns with developing such a teamoriented community/class room is the performance of an individual when independent of the group. As noted, there were individual (tests and exam) and partnered (lab reports) evaluations. It was observed that students generally performed better on their lab reports than on their tests/exam. Of course, it is difficult to make any definitive conclusions about the grade discrepancy as lab reports assess a very different type of performance than tests/exams. However, there is concern that the nature of our tutorial, which encourages group work, has students forgetting that they still need to attempt problems independently as this will eventually be how they are assessed at large.

One potential solution currently under consideration is the 
inclusion of more individual assessments through out the term, either through quizzes or graded assignments. The conflict then becomes a matter of resource management, as the grading of additional individual assessments will require significant time, that may only be achievable through the reduction of contact time in-tutorial, negating the benefits of the personalized coaching we have been able to employ.

\section{SUMMARY}

When attempting to deliver a large amount of content, especially to students who may not be appropriately prepared, there are many inherent struggles in identifying ideal mechanisms for knowledge transfer. We looked to improve student understanding by creating a group learning atmosphere during tutorial times, where small groups of students were encouraged to brainstorm on whiteboards and come to consensus solutions to pre-assigned problem sets. The think aloud process was augmented with our white board environment. It enables instructors in the room to readily observe the progress of many students at once, and strategically choose when to step in for some coaching. Stepping in the moment progress deviates or slows reinforces that there is a single, linear solution path to all problems it reinforces an incorrect perception of the problem analysis process. Stepping in too late has students wasting time and losing confidence. Additionally, this approach allowed us to easily identify significant gaps of understanding which allowed instructors to modify their approaches to best support the students. However, there were still many concerns, including the difficulty of engaging timid students, and more concerning, the issue of students being unable to perform at a strong level away from the comfort of the group learning atmosphere. These concerns will continue to be deliberated in the hopes of further improving content delivery strategies.

\section{Acknowledgements}

The authors would like to thank the students of ENGG 2560 W13 for their participation in Environmental Engineering Systems and constructive feedback through out the term.

\section{References}

[1] "2009 accreditation crieteria and procedures," tech. rep., Engineers Canada, Canadian Engineering Accreditation Board, Ottawa, CAN. ISSN 1708-8054,86p.

[2] ABET, "Criteria for accrediting engineering programs," 2010. [Online; accessed May 2010].

[3] W. A. International Engineering Alliance, "Washington accord rules and procedures," 2007. [Online; updated 13-August-2007].

[4] J. S. M.W. Van Someren, Y.F. Barnard, The Think Aloud Method: A practical guide to modelling cognitive process. London: Academic Press, 1994. 208p.

[5] A. W. J. Lockhead, "Teaching analytical reasoning through thinking aloud pair problem solving," New $\mathrm{Di}$ rections, vol. 30, 1987.

[6] U. of Guelph, "2012-2013 university of guelph undergraduate calendar," 2013. [Online; accessed 23-April2013]. 